\title{
Research on the Influence of Stability of Tailings Dam Under Muddy Water Infiltration
}

\author{
Zhifei Song $^{1, \text { a }}$, Jianqiang Wang ${ }^{2, b}$, Jianyi Zhang ${ }^{3, c}$ and Faliang Zhao ${ }^{4, d}$ \\ ${ }^{1}$ North China University of Technology,Beijing, China \\ ${ }^{2}$ North China University of Technology,Beijing, China \\ ${ }^{3}$ North China University of Technology,Beijing, China \\ ${ }^{4}$ North China University of Technology,Beijing, China

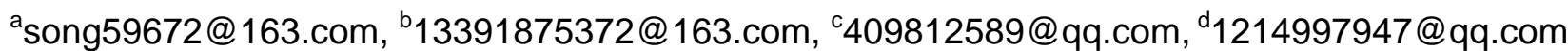

Keywords::Muddy water infiltration,Seepage line,Permeability coefficient,Size distribution,Siltation effect, Safty factor.

Abstract. The penetration of the tail slurry suspended particles leads to the phenomenon of clogging, a higher seepage line and impact on stability of tailings dam. First of all, study influencing factors of muddy water infiltrationan, then an indoor simulation experiment is conductedaccording to the former study, using a self-made muddy water seepage test instrument, and the evolution lawsof the coefficient of permeability of muddy water infiltration is analyzed, utilize it to correct related design parameters of a tailings dam, estimate the permeability function through particle size distribution curve which is obtained by laser particle size analyzer.By using the original and the adjusted parameter for simulation of the seepage field, the position and form of saturation line under two kinds of situations are obtained,and by using strength reduction finite element method,dam body stability is simulated under three kinds of working conditions at the time of the high end,the result is that the stability safety coefficients all decreased obviously when considering the muddy water seepage law.Thus, the stability of tailings dam can be reduced by the deposition of silt.

\section{Introduction}

Tailings discharge in the form of slurry.Actually,the tailings is a tailings dam of artificial lake. Most of the suspended particles in the slurry settlement dry on the beach, the rest of it deposit on the bottom, and affect the seepage ability of dam continuously. There are many analysis methods for the seepage problems, however,there still exists certain limitations of these methods. Most of the research focuses on the water seepage at home and abroad, though some scholars studied the muddy water seepage, but the results are mostly regularity. The seepage mathematical model which was proposed, often is only applicable to the specific project without generalityl ${ }^{[1]}$. Simulate dam siltation phenomenon by using self-made muddy water seepage test instrument of muddy water seepage, use a laser particle size analyzer to obtain particle size distribution, and the stability of arch dam under the high end when considering siltation are numerical analyzed.

\section{The impact analysis of muddy water infiltration}

The parameters of permeability coefficient of tailings dam stability calculation,generally refer to the relevant specification, geotechnical engineering investigation report or similar engineering design ${ }^{[2]}$. It has neither considered the effect of muddy water infiltration, also the parameters of time-space effect, and the exploration data is often uneven ${ }^{[3]}$. The permeability coefficient of tailings dam, actually changes with the process of muddy water infiltration ${ }^{[2]}$. Therefore, considering the influences of muddy water infiltration, it has important engineering significance for the safety assessment of tailings dam.

The variation of location of the dam saturation line, determine whether the seepage during operation is normal, the dam is stable.There are serval main factors influencing the tailings dam saturation line position, such as reservoir water level, the early dam dam type, characteristics of 
stacking dam, drainage in dam foundation, stratification of tailings, penetration characteristics and sedimentary slope beach, etc ${ }^{[4]}$. Among them, penetration characteristics of tailings, reservoir level,sedimentary slope beach and stratification of the tailings are greatly influenced by muddy water infiltration.

The characteristics of tailings infiltration is complex.The permeability coefficient of different types of dam appear large differences ${ }^{[5]}$. At the same time, the vertical permeability and horizontal permeability coefficient of tailings is also quite different. Therefore, under the influence of muddy water seepage, tailings penetration characteristics will appear larger changes. Siltation caused by the effect of muddy water infiltration will directly cause the decreaseof the drainage ability, higher water level.In different concentration and particle size distribution, under the muddy water discharge process of tailings ,tailings deposition layering clutter, and sedimentary slope beach can subsequently change, and directly affect the position of saturation line, thus affect thestability of dam slope .

\section{The indoor experiment}

\section{1 test design}

Simulate the flow of muddy water infiltration process with the self-made tester of muddy water seepage in the indoor simulation test, as shown in figure 1. The instrument consists of muddy water preparation system, automatic mixing system and test of the sand column. Figure $1 \mathrm{On}$ the left of figure 1 is the automatic mixing muddy water preparation system, intermediate is electromagnetic flowmeter and the water pump, the right isthe test the sand column. The material of sand column adopt tail mineral sand with size of $0.5-1 \mathrm{~mm}$ diameter range

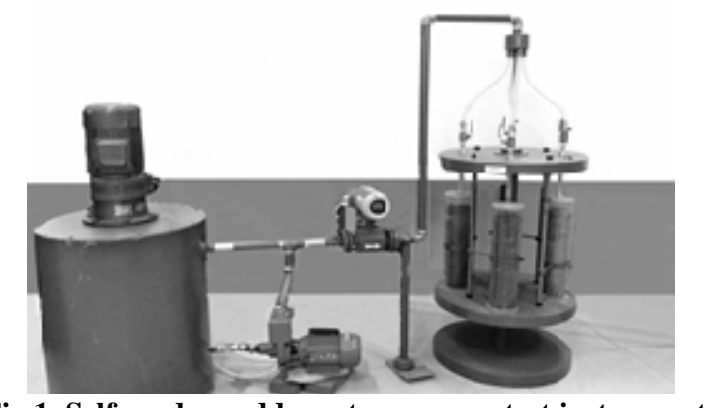

Fig.1 Self-made muddy water seepage test instrument

For particle size $\mathrm{d}>1 \mathrm{~mm}$ and $\mathrm{d}<0.5 \mathrm{~mm}$,adopt super size particle processing method.Modify the existing gradation curve, in order to ensure grading curve, uniformity coefficient and coefficient of curvature is consistent with the actual distribution curve, especially adopt the way of eliminating method and the equivalent substitution method, to ensure the authenticity of the test ${ }^{[6]}$.

The choosen size of muddy water particles should be less than $0.155 \mathrm{Di}$ (Di:maximum particle size of sand column values), taking $1 \mathrm{~mm}$ as the value of Di. Therefore, the maximum size of particle is $0.155 \mathrm{~mm}$. Select a standard screen close to the aperture size of $0.15 \mathrm{~mm}$. The quality concentration of muddy water respectively adope the clear water, $5 \%, 15 \%$. Test head:50 cm, $100 \mathrm{~cm}$, respectively. Test scheme is shown in table 1.

Table 1 Muddy water seepage test scheme

\begin{tabular}{cccc}
\hline number & concentration/\% & test head $/ \mathrm{cm}$ & particle size $/ \mathrm{mm}$ \\
\hline (1) & 0 & 50 & $0.5-1$ \\
$(2)$ & 5 & 50 & $0.5-1$ \\
$(3)$ & 15 & 50 & $0.5-1$ \\
$(4)$ & 15 & 100 & $0.5-1$ \\
\hline
\end{tabular}

\section{2 test results and conclusions}

The test results is shown in the form of chart: the variation of permeability coefficient with time,in figure 2 . 


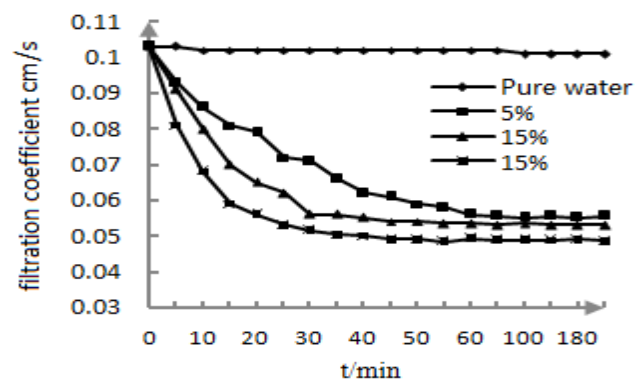

Fig.2 The curve of the coefficient of permeability changing with time

From figure 2, in the process of water infiltration, the permeability coefficient of sand column has no obvious change, reflecting good stability of sand column coefficient of permeability in the process of water infiltration. However,it has big differences under the muddy water infiltration. The permeability coefficient of sand column decreased in a large degree under different conditions along with time, lower rate is gradually reduced, and tends to be stable finally. And with the increase of the concentration, the reducing rate and amplitude of permeability coefficient are increasing. With the increase of water head height, the reducing rate and amplitude are also on the increase. After stability of infiltration, the coefficient permeability of each sand column converges.

Conclusion: under water infiltration, permeability coefficient of sand column basically unchanged. Under different concentrations and water head height, the change form and the trend of the permeability coefficient is consistent, namely as the stability of seepage, the permeability coefficient tend to a fixed value respectively, with little difference. The speed of decreasing increases with the increase of the height of water head,and concentration of muddy water respectively ${ }^{[7]}{ }^{[8]}$.

Based on the general equation, which is used to describe the variation of permeability coefficient in porous media proposed by Bianchi ${ }^{[9]}$, the fitting formula (1) of the variation of permeability coefficient is obtained.

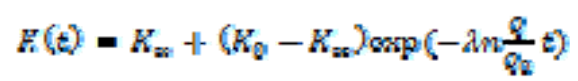

Among them: $K_{0}:$ the initial permeability coefficient, $K_{s}$ :the final permeability coefficient; $\lambda:$ a correction coefficient, referring to the material properties, porosity, pore surface area and tortuosity of the medium . $N$ : concentration of muddy water; $Q$ : seepage flow; $Q_{0}$ : the initial seepage flow; t:time.

\section{4 engineering examples}

\section{1 project summary}

The tailings dam is built by upstream method, the initial dam is $15 \mathrm{~m}$, elevation of $232.7 \mathrm{~m}, 288.7 \mathrm{~m}$ high,hight $\mathrm{H}=78.7 \mathrm{~m}$. Upstream slope ratio of $1: 1.6$, the downstream slope ratio of $1: 1$. 5 . The total capacity below $288.7 \mathrm{~m}$ is about 10 million $\mathrm{m}^{3}$. According to "the tailings in safety technical regulations "(AQ2006-2005) ${ }^{[10]}$ :dam hight $\mathrm{H}=78.7 \mathrm{~m}, 60 \mathrm{~m} \leq \mathrm{H}<100 \mathrm{~m}$; the total capacity $\mathrm{V}=10$ million $\mathrm{m}^{3}, 1000$ million $\mathrm{m}^{3} \leq \mathrm{V}<10000$ million $\mathrm{m}^{3}$, the present situation of tailings as the third class library.

\section{2 stability analysis}

\subsection{1 analysis software}

Geo-Studio has been widely applied to the design and analysis of geotechnical engineering. Apply SEEP/W module to simulate seepage field, mainly on normal working condition, the highest flood and earthquake three working conditions on whether consider the influence of the muddy water seepage. Then make a contrast of the position of saturation line. The simulation results are substituted into the SLOPE/W module to conduct stability analysis, and find out the most dangerous sliding surface position and safety coefficient ${ }^{[11]}$, compare the safety factor of these three cases. 


\subsection{2 calculation model and parameters}

(1)Section model: take the maximum section perpendicular to the axis of the dam as calculation model.

(2)The physical and mechanical parameters of materials without muddy water seepage. In accordance with the law in the process of deposition of the upstream tailings dam, and "the specification for design of concentrator tailings facilities" (ZBJ1-90) ${ }^{[12]}$ and physical and mechanical parameters of the soil, list the required calculation parameters in table 2.

Table 2 Mechanical parameters of tailings dam

\begin{tabular}{|c|c|c|c|c|c|c|c|c|c|c|}
\hline \multirow[t]{2}{*}{ Material } & \multicolumn{2}{|c|}{$\begin{array}{l}\text { Natural bulk } \\
\text { density } /\left(\mathrm{kN} / \mathrm{m}^{3}\right)\end{array}$} & \multicolumn{2}{|c|}{$\begin{array}{c}\text { Saturated bulk } \\
\text { density } /\left(\mathrm{kN} / \mathrm{m}^{3}\right)\end{array}$} & \multicolumn{2}{|c|}{ friction angle/( $\left.{ }^{\circ}\right)$} & \multicolumn{2}{|c|}{ Cohesion $/(\mathrm{kPa})$} & \multicolumn{2}{|c|}{$\begin{array}{c}\text { Permeability } \\
\text { coefficient } /\left(\times 10^{-4} \mathrm{~cm} /\right)\end{array}$} \\
\hline & A & $\mathrm{B}$ & $\mathrm{A}$ & $\mathrm{B}$ & A & $\mathrm{B}$ & A & $\mathrm{B}$ & A & $\mathrm{B}$ \\
\hline Initial dam & 18.0 & 18.4 & 20.0 & 20.4 & 38 & 39 & 0.0 & 0.0 & 2.0 & 1.6 \\
\hline Fine sand & 16.3 & 16.9 & 19.6 & 20.2 & 35 & 37 & 0.0 & 5.0 & 13.0 & 5.6 \\
\hline Tail powder & 15.9 & 16.3 & 19.5 & 19.9 & 33 & 34 & 0.0 & 9.0 & $5.0 \quad 2$ & .8 \\
\hline Silt soil & 15.6 & 15.9 & 19.4 & 19.6 & 32 & 33 & 8.0 & 11.0 & $2.5 \quad 1.5$ & \\
\hline Gravel soil & 17.0 & 18.5 & 20.0 & 20.9 & 28 & 31 & 15.0 & 16.5 & 7.0 & 6.3 \\
\hline $\begin{array}{c}\text { Strong } \\
\text { weathered rock }\end{array}$ & 18.0 & 18.0 & 20.0 & 20.0 & 35 & 35 & 35.0 & 35.0 & 1.0 & 1.0 \\
\hline
\end{tabular}

Note: 1 "A" column "refers to parameter of initial material of the dam body.

2 "B" column "refers to parameters which consider physical clogging.

(3)The physical and mechanical parameters of materials under the influence of muddy water seepage,mainly according to the results of laboratory test, the trend analysis of related parameters, and comparison to similar engineering design, in order to modify mechanical properties of the layers of tailings. The correction results are shown in table 2 .

(4) the determination of permeability coefficient function. Using Geo - Studio software SEEP/W module of the finite element model is established, and the determination of permeability coefficient are the main difficulties of the parameters. In fact, infiltrating offline the permeability coefficient of dam in saturated state, the permeability coefficient and the survey report to a constant. And saturation line above the dam is in unsaturated condition, the permeability coefficient varies with parameters such as the matrix suction and moisture content changes. As a result, the permeability coefficient functions of the reasonable, is very important to the numerical simulation. This article take the particle size distribution curve to volumetric water content function, the technical route of permeability function.

The particle size distribution curve is usually achieved by sieving method and sedimentation analysis method However this method is cumbersome time consuming without quick results.Apply the laser particle size analyzer for particle size distribution. Then conduct numerical simulation by inputing characteristics of the particle size to SEEP/W module to estimate the volumetric water content function. Finally, select the Van Genuchten method to calculate the volumetric water content function.

According to the principle:

$$
\theta_{w}=\theta_{r}+\frac{\theta_{s}-\theta_{r}}{\left[1+\left(\frac{\psi}{a}\right)^{m}\right]^{m}}
$$

Among them, $m=1-1 / n$ and $0<m<1, \theta_{w}$ : the volumetric water content, $\psi$ :negative pore water pressure, $\theta_{s}$ :volume of saturated water content, $\theta_{r}$ :residual humidity, $a 、 n 、 m$ : curve fitting parameters, the unit of $a$ is kpa, $n 、 m$ :dimensionless.

According to function (2), volume moisture content and matrix suction pore water pressure (negative) images are available,thus the process of the particle size distribution curve to the volumetric water content of the counting has been completed. Then, with the comprehensive 
consideration of the coefficient of permeability, pore water pressure, water content, volume estimation method, the permeability functions is determined.

\subsection{3 stability analysis}

(1)Position of saturation line. The position of saturation line of tailings dam high end during normal working conditions are shown in figure 3, figure 4. Comparing saturation line in two cases: when considering influence of muddy water seepage, the position of saturation line got higher raisen, seepage path shortened, hydraulic slope steepened, leakage point location increasing ${ }^{[13]}$.
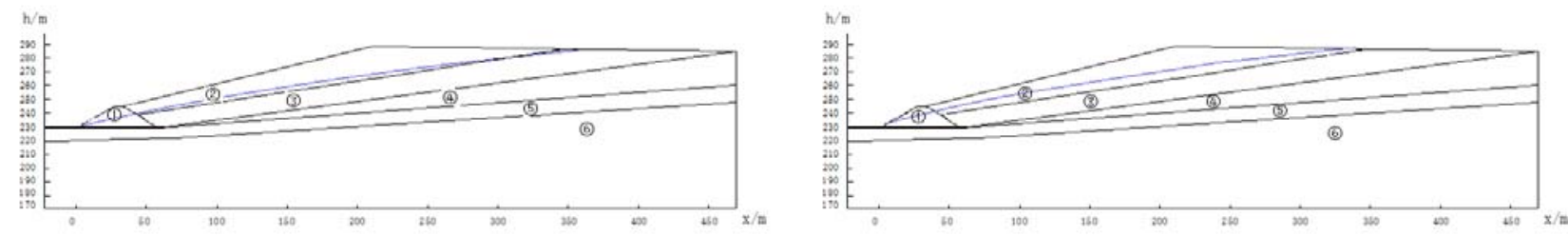

Fig.3 Not considering the influence of muddy water seepage saturation line position

Fig. 4 Considering the influence of muddy water seepage saturation line position

(2)Stability safety factor.Import three SEEP/W results into SLOPE/W to conduct stability analysis. List the results in table 3.

Table3 High end dam body safty factor of stability

\begin{tabular}{cccc}
\hline working condition & standard & $\mathrm{A} / \mathrm{B}$ & evaluation \\
\hline normal & 1.20 & $1.459 / 1.242$ & satisfied / satisfied \\
Flood & 1.10 & $1.298 / 1.043$ & satisfied / not satisfied \\
earthquake & 1.05 & $1.196 / 0.897$ & satisfied / not satisfied
\end{tabular}

Comparing the safety coefficient of two kinds of circumstances, it is concluded that, after consideration of muddy water infiltration, three kinds of safety coefficient decreased in a certain degree.under normal condition: it was reduced by $14 \%$, the highest flood condition:by $19 \%$, the earthquake condition by $25 \%$; The safety factor under normal working condition meets the requirements, the other two cases do not meet the requirements.

\section{Conclusion}

(1)Through the indoor experiment, the infiltration law of tail ore column under different water head heightand concentrations of muddy water has been obtained, and the evolution equation is given. The experimental results show that the sand column under different concentrations and head of permeability coefficient is a constant, and the higher the water head, the greater the concentration, the smaller the permeability coefficient of the final. The composition of the final value mainly accord with the coefficient of permeability of sand column structure, grain size distribution.

(2)Through modifying design parameters to simulate the influence of muddy water infiltration on the dam, the position and form of saturation line of final dam is obtained. Compared with the case ignoring the effect of muddy water infiltration, the position of saturation line get a degree of ascension, the seepage path shortened, , hydraulic grade steepened, leakage point location increasing.

(3)After considering the effect of muddy water infiltration, the stability safety factor meet the requirements only on normal working condition. The safety coefficient under the flood level and the earthquake does not meet the requirements. It indicates that the siltation effects of muddy water infiltration reduces the flood prevention and seismic capacity of dam, and poses a serious threat to the stability of dam body.

\section{Acknowledgements}

This work was financially supported by the national natural science foundation of China (41202214), Beijing science and Technology Star Program (Z121106002512008). 


\section{Reference}

[1] Jiang Donghui,SunQiang,ZhuShuyun, et al.Analysis on the Behavior of Rock Permeability along Whole Stress-strain Path[J].Metal Mine,2012(2);22-24.

[2] Jin Jiaxu.Stability analysis of tailings dam under the muddy water infiltration [D]. Fuxing: Liaoning Technical University,2009.

[3] Zhou Zhenming,LiXiangyuan. The cause of tailings dam accident and ecological environmental impact assessment in China[J].2012 (11) ;121-124.

[4] Wu Qinming,et al.Calculationand analysisofa tailing dam'sstability[J].Nonferrous Metals (Mining Section), 2010,62(2):63-66.

[5] WangFeiyue, YangKaiteng,etal.Stability analysis of tailings dam based on saturation line matrix

[J]. Rock and Soil Mechanics, 2009,30(3):840-844.

[6] Yao Lei.Experimental study on remainer during muddy water infiltrating[D].Beijing:Tsinghua Univesity,2004.

[7] Dang Faning,LiuYunhe,ChenJuniang, et al.Muddy water seepage theory and engineering application[J].ScientiaSinicaTechnologica, 2006,36(9):1029-1036.

[8] Ma Chixiang,QinHuali,XuShufang, et al. Study on the seepage field of tailing dam based on water-soil interaction[J].Metal Mine,2009(5);168-171.

[9] Bianchi W C,Nightingale H I, McCormick R L, A case history to evaluta the performance of waterspreading projects[J].Journal of the American Water Workes Association, 1978, 30(3): 176 -180 .

[10] Safety technical regulations for the tailing pond(AQ 2006-2005)[S].Panzhihua:State administration of production safety supervision and management,2005.

[11] Song Zhifei,WangQun,ZhaoXuefang, et al. Numerical analysis of the stability of tailings dam[J].Industrial Safety and Environmental,2015,41 (1): $42-47$.

[12] Concentrator tailings facilities design specification(ZBJ1-90) [S].Beijing:BeijingNonferrous Metallurgy Research Institute, 1991.

[13] Chen Xing. Influence of permeability coefficient ratio of tailings dam on saturation line[J]. Nonferrous Metals(Mining Section),2011,63(6):58-61. 